\title{
Crystalglobulin-associated nephropathy presenting as MGRS in a case of monoclonal B-cell lymphocytosis: a case report
}

\author{
Rajib K. Gupta* ${ }^{* *}$, Lois J. Arend ${ }^{2}$, Anupama BK ${ }^{3}$, Sriram Narsipur ${ }^{4}$ and Ramya Bhargava ${ }^{5}$
}

\begin{abstract}
Background: Crystalglobulin-associated nephropathy (CAN), a rare subtype of monoclonal gammopathy, usually associated with multiple myeloma and occasionally monoclonal gammopathy of uncertain significance (MGUS), is characterized by occluding monoclonal pseudothrombi within renal glomerular capillaries and/or interstitial arterioles. Ultrastructurally, these pseudothrombi are unique for having a crystalline substructure. We describe a case of an adult patient with monoclonal B-cell lymphocytosis (MBL) and acute renal failure whose kidney biopsy revealed a rare diagnosis of CAN.
\end{abstract}

Case presentation: A 63-year old male presented with a 2-month history of edema, arthralgia and malaise. He had acute kidney injury with hematoproteinuria on urine analysis. Serum and urine protein electrophoresis were both negative. A renal biopsy however revealed features of CAN. Organomegaly, bone pain and lymphadenopathy were absent. A repeat serum electrophoresis was positive for IgA kappa and a free light chain assay showed elevated free kappa light chains. Flow cytometry done subsequently revealed a diagnosis of MBL, chronic lymphocytic leukemia (CLL) type.

Conclusion: CAN in association with MBL/CLL has not been previously described in literature, and our case highlights yet another instance of monoclonal gammopathy of renal significance (MGRS) where a small B-cell clone resulted in extensive renal pathology without systemic manifestations.

Keywords: Crystalglobulin-associated nephropathy, Monoclonal B-cell lymphocytosis, Monoclonal gammopathy of renal significance

\section{Background}

Crystalglobulin-associated nephropathy (CAN) is a monoclonal immunoglobulin light chain-related rare renal disease characterized by large extracellular crystals of paraproteins presenting as occluding thrombi (pseudothrombi) within glomerular capillaries and/or renal

\footnotetext{
* Correspondence: rajibgupta2011@gmail.com

'Department of Pathology, SUNY Upstate Medical University, 750 E Adams Street, Syracuse, NY 13210, USA

Full list of author information is available at the end of the article
}

interstitial arterioles $[1,2]$. Sometimes CAN is associated with a circulating monoclonal protein with cryoglobulinlike properties resulting in small vessel occlusion and inflammation in the systemic microvasculature, when it is known as crystalglobulinemia or cryocrystalglobulinemia [1]. In published literature, CAN has been described mainly in association with frank multiple myeloma (MM) or monoclonal gammopathy of undetermined significance (MGUS) [1]. We describe a rare case report of a patient with a small clonal B-cell population (also known as

C C The Author(s). 2020 Open Access This article is licensed under a Creative Commons Attribution 4.0 International License, which permits use, sharing, adaptation, distribution and reproduction in any medium or format, as long as you give appropriate credit to the original author(s) and the source, provide a link to the Creative Commons licence, and indicate if changes were made. The images or other third party material in this article are included in the article's Creative Commons licence, unless indicated otherwise in a credit line to the material. If material is not included in the article's Creative Commons licence and your intended use is not permitted by statutory regulation or exceeds the permitted use, you will need to obtain permission directly from the copyright holder. To view a copy of this licence, visit http://creativecommons.org/licenses/by/4.0/. The Creative Commons Public Domain Dedication waiver (http://creativecommons.org/publicdomain/zero/1.0/) applies to the data made available in this article, unless otherwise stated in a credit line to the data. 
monoclonal B-cell lymphocytosis or MBL) who developed acute renal failure from CAN requiring long term hemodialysis. CAN presenting as a monoclonal gammopathy of renal significance (MGRS) in a MBL patient has not been described previously in literature.

\section{Case presentation}

A 63-year-old male with hypertension and seizure disorder presented to the renal clinic with a blood pressure of $220 / 110 \mathrm{mmHg}$, headache and neck pain and was sent to the emergency department. His review of systems showed that he had a 2-month history of bilateral ankle pain, anasarca, progressive renal impairment, weakness and fatigue, associated with a history of loss of appetite for this period of time. A renal workup revealed nephroticrange proteinuria and microscopic hematuria, with urinalysis showing red cells and protein. CBC showed a hemoglobin of $8.6 \mathrm{~g} / \mathrm{dL}$, white cell count of $7.7 \mathrm{~K} / \mathrm{uL}$ and a platelet count of $146 \mathrm{~K} / \mathrm{uL}$. Blood chemistry showed sodium of $146 \mathrm{mmol} / \mathrm{L}$. potassium of $4.5 \mathrm{mmol} / \mathrm{L}$, bicarbonate of $25 \mathrm{mmol} / \mathrm{L}$, chloride of $113 \mathrm{mmol} / \mathrm{L}, \mathrm{BUN}$ of 61 $\mathrm{mg} / \mathrm{dL}$ and a creatinine of $4.08 \mathrm{mg} / \mathrm{dL}$. Serology was negative for antinuclear antibody, antineutrophil cytoplasmic antibodies, rheumatoid factor, anti-double stranded DNA antibody, lupus anticoagulant, cryoglobulins and viral markers (HBV, HCV and HIV). Complement levels were normal. Serum and urine protein electrophoresis were negative for a monoclonal protein. Although he had slightly low haptoglobin, his ADAMTS13 level was within normal limits. A renal core biopsy showed predominantly medulla and a small cortical sample, containing up to 12 glomeruli of which one glomerulus was globally sclerosed. All patent glomeruli showed segmental or global occlusion of capillary loops by PAS-positive eosinophilic pseudothrombi which were non-argyrophilic and stained magenta red on trichrome (Fig. 1a-c); some of the glomeruli had a membranoproliferative pattern associated with mild mesangial hypercellularity and segmental double contours (Fig. 1b, PAS stain). A single artery sampled showed moderate arteriosclerosis but no thrombi. The interstitium was unremarkable except for patchy fibrosis. On immunofluorescence microscopy (IF), the pseudothrombi stained for IgA, kappa and lambda (Fig. 1d-f) and were negative for the other immunoreactants; some pseudothrombi also showed intensely staining bright foci that were more numerous in kappa than in lambda (arrow). Electron microscopy (EM) of 2 glomeruli showed several capillary loops lined by swollen endothelial cells, with occluding intraluminal electron-dense crystals; all the crystals showed a lattice-like substructure with parallel linear arrays. No

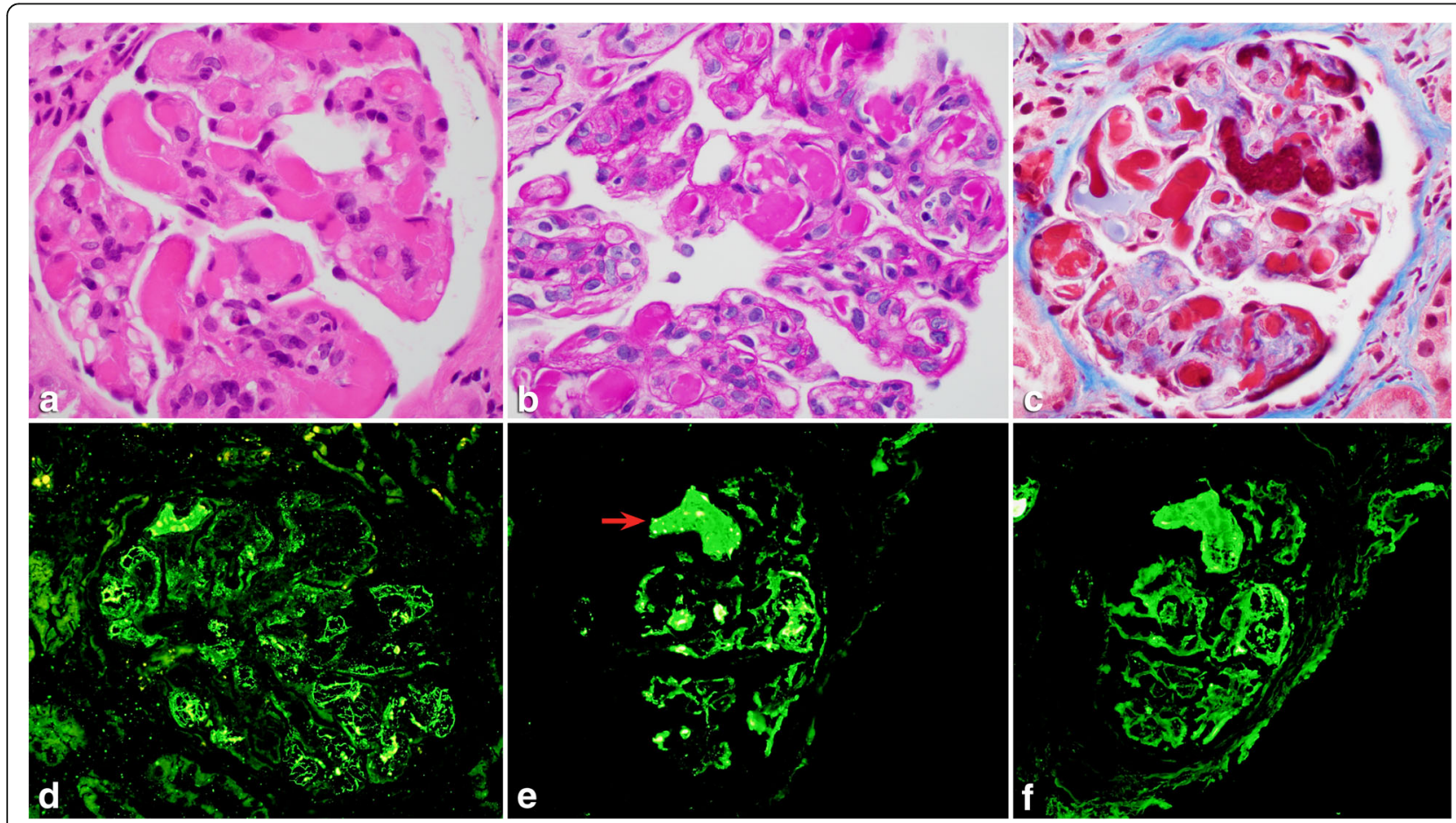

Fig. 1 Light and immunofluorescence microscopy images: a. H\&E section showing a representative glomerulus with capillary loops obstructed by pseudothrombi, X 600; b-c. PAS (b) and Masson trichrome (c) stained sections showing segmental to global occlusion of glomerular capillaries by pseudothrombi, $X 600$. The glomerulus in $\mathbf{b}$ also shows segmental double contours, and has a membranoproliferative appearance; $\mathbf{d}$-f $\mathbf{I}$ Immunofluorescence staining for $\lg \mathrm{A}(\mathbf{d})$, kappa $(\mathbf{e})$, and lambda (f) showing staining of the pseudothrombi for lgA, kappa, and lambda, with similar intensity. Within some pseudothrombi are intensely stained foci that are more numerous for IgA and kappa than lambda (arrow in image e) 
conventional immune complex-type electron-dense deposits or fibrin tactoids were seen within the glomeruli (Fig. 2a-c). Crystals were also not seen within proximal tubular epithelial cells. Occasional loops showed mild subendothelial widening along with rare cell interposition. A diagnosis of crystalglobulin-associated nephropathy (CAN) with possible kappa restriction was favored. Paraffin-IF with pronase digestion could not be performed as no glomeruli remained in the paraffin block. Subsequent testing with immunogold EM showed preferential association of kappa particles for the crystals, confirming kappa restriction of the crystals (Fig. 2d-f). A repeat serum electrophoresis 3 months later showed IgA kappa and trace amount of IgG lambda while urinary protein electrophoresis remained negative; a free light chain assay showed a kappa/lambda ratio of 3.9. Bone marrow and peripheral blood flow cytometry at this time showed a small clonal B-cell population $(0.19 \mathrm{~K} / \mathrm{uL})$ with kappa restriction and a chronic lymphocytic leukemia (CLL) phenotype, co-expressing CD5 and CD23 and being negative for CD10 and CD103. No organomegaly or lymphadenopathy was present in the patient. A diagnosis of CAN presenting as MGRS in the background of monoclonal B-cell lymphocytosis (MBL) was confirmed in the patient. Since the diagnosis, the patient has been dialysis-dependent. A hemato-oncology referral was sought in view of the patient's MGRS finding but because of the low clonal B-cell count coupled with extreme frailty and recurrent episodes of C.difficile diarrhea in the patient, no specific hematologic treatment was decided to be initiated by the clinical team till the patient became clinically more stable.

\section{Discussion and conclusion}

Monoclonal gammopathies causing renal lesions may be caused by an underlying hematologic disease which, in turn, may be frankly malignant conditions like symptomatic $\mathrm{MM}$ or a B-cell lymphoma or premalignant states like smoldering myeloma, MGUS and MBL (the B-cell counterpart of MGUS) [3]. Renal pathology in association with all premalignant hematologic diseases is now considered under the umbrella of MGRS [2, 3]. While MGRS in association with MGUS has been known for some time now, MGRS caused by nephrotoxic paraproteins released by premalignant small B-cell clones has only recently gained attention [3].

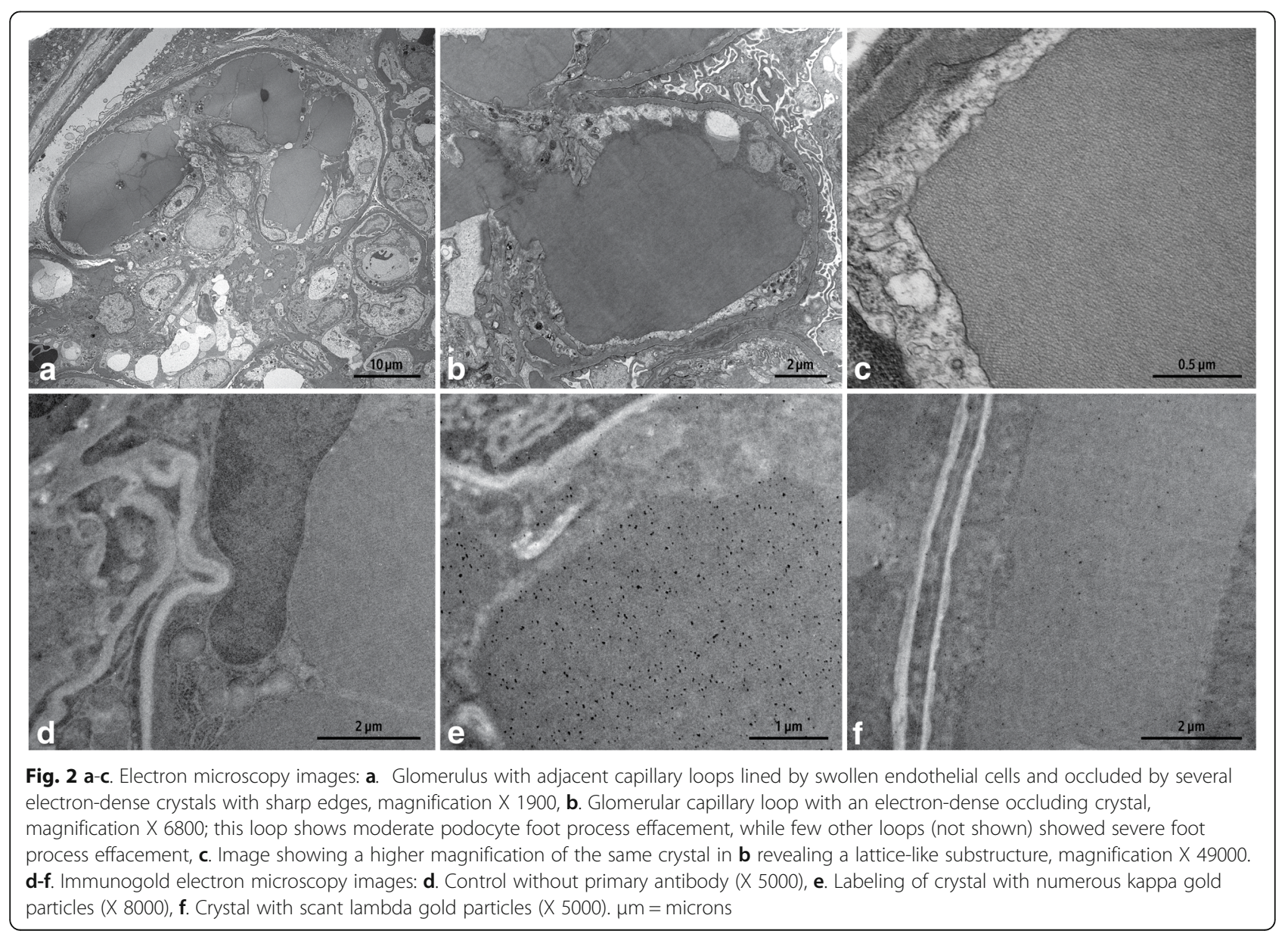


CAN is a rare paraprotein crystal-induced renal disease caused by glomerular intracapillary and renal arteriolar occlusion by crystals, the other subtypes of paraprotein crystal-induced nephropathies include crystalline variant of light chain proximal tubulopathy (intracellular light chain crystals precipitating within the proximal tubular epithelial cells and often associated with Fanconi syndrome) [2, 4], monoclonal crystalloid glomerulopathy (intracellular light chain crystals within individual glomerular cell compartments like endothelial cells or podocytes) [5-7] and crystal-storing histiocytosis (light chain crystal-bearing histiocytes found either in interstitium, mesangium or glomerular capillary loops), as highlighted in Fig. $3[8,9]$. Although there have been case reports of crystalglobulinemia since 1930s [10], it is only recently that a specific renal lesion in association with these extracellular circulating crystals has been delineated [1]. CAN has been described mostly in association with MM and MGUS [1,11]. Our report describes a rare case of CAN associated with MBL (with CLL phenotype) presenting as MGRS in a patient with acute renal failure leading to hemodialysis. A B-cell clone under $5 \mathrm{~K} / \mathrm{uL}$ falls under the MBL category as per latest WHO guidelines [12], and our patient's clonal B-cell count was quite low, at $0.19 \mathrm{~K} / \mathrm{uL}$. Two large case series $[13,14]$ which have studied the spectrum of renal lesions associated with CLL/MBL have described various MGRS entities such as cryoglobulinemic glomerulonephritis (GN), immunotactoid GN, fibrillary GN, amyloidosis and light chain cast nephropathy, but CAN developing as a result of CLL/MBL has not been described previously. A 2014 series of 20 cases of non-Hodgkin lymphoma with biopsy-proven renal involvement describes a single case of CLL having light microscopy appearance similar to ours with intracapillary plugging by PASpositive pseudothrombi which stained for IgM and kappa by IF but on EM, showed only granular electrondense deposits occluding the capillary loops but without any substructure [15].

Histologically, the renal biopsy in CAN shows glomeruli with large intracapillary eosinophilic pseudothrombi with or without glomerular hypercellularity while endocapillary hypercellularity has been variably described, mesangial hypercellularity (present in our case) has not been described in previous case reports $[1,11]$. Segmental capillary wall double contours were described in one case [16]. The double contours seen in the glomeruli by light microscopy (and corroborated by subendothelial widening seen in some capillary loops on EM) were likely the result of endothelial injury from the patient's severe hypertension or direct injury from the intraluminal occluding crystals, or both. Although classic features of thrombotic microangiopathy (TMA) such as fibrin thrombi or mucoid intimal thickening were not seen within the glomeruli or vasculature sampled (only one artery being present in the biopsy), the possibility of a monoclonal gammopathy-associated TMA cannot be completely excluded [17]. Frozen section immunofluorescence (IF) can be challenging to interpret in cases of CAN (as was in our case) and, where available, paraffin IF with pronase digestion, has been recommended as a more sensitive IF technique in such cases [18]. However, immunogold EM (IEM), can also serve as an alternative and equally (if not more) sensitive technique for confirming monoclonality of crystalline deposits by actually localizing kappa or lambda light chains within the crystals $[8,19,20]$. In our case, IEM proved indispensable in confirming the kappa restriction of the light chain intraluminal crystals. IEM for immunoglobulins was not attempted as it not standardized in the electron microscopy lab where the IEM procedure was done, and it has not been well described in literature $[19,20]$. Patients with CAN (particularly those with cryocrystalglobulinemia) may develop symptoms like rash, arthralgia and peripheral neuropathy as usually seen in patients with cryoglobulinemic and rheumatic diseases [1], and even renal arterial thrombosis in rare instances [11]. Our patient had arthralgia but none of the other symptoms. Usually, kappa predominates as the restricted light chain that is overproduced in monoclonal crystal-related nephropathies $[1,11]$, although occasional lambdapredominant cases have been reported [16].

The histologic differential diagnoses for our case included - TMA associated with various etiologies like hemolytic-uremic syndrome, complement abnormality, malignant hypertension, autoimmune diseases (including antiphospholipid antibody syndrome) or solid malignancies, type 1 cryoglobulinemic glomerulonephritis secondary to kappa monoclonal disease or staphylococcal infection-related glomerulonephritis (SAGN) with cryoglobulinemic features. However, in none of these conditions are actual monoclonal crystals with lattice substructure found within capillary loops on EM as was seen in our case [21, 22]. Also in our case, the patient had no recent history of infection or pre-existing diabetes to support a diagnosis of SAGN.

The exact pathologic/biochemical basis of crystallization of monoclonal proteins and the reason for kappa predominance are not well understood. However researchers have suggested possible abnormal $\mathrm{N}$-glycosylation of the light chain portion of monoclonal paraproteins, aided by stasis in microvasculature as the reason for crystal formation [23], while unusual hydrophobic residues at the variable (V) domain of the kappa light chain at position 30 or unusual amino acid substitutions in the $\mathrm{V}$ region have been cited as a reason why the kappa crystals are resistant to normal lysosomal degradation in the B- or plasma cellmicroenvironment [24]. 


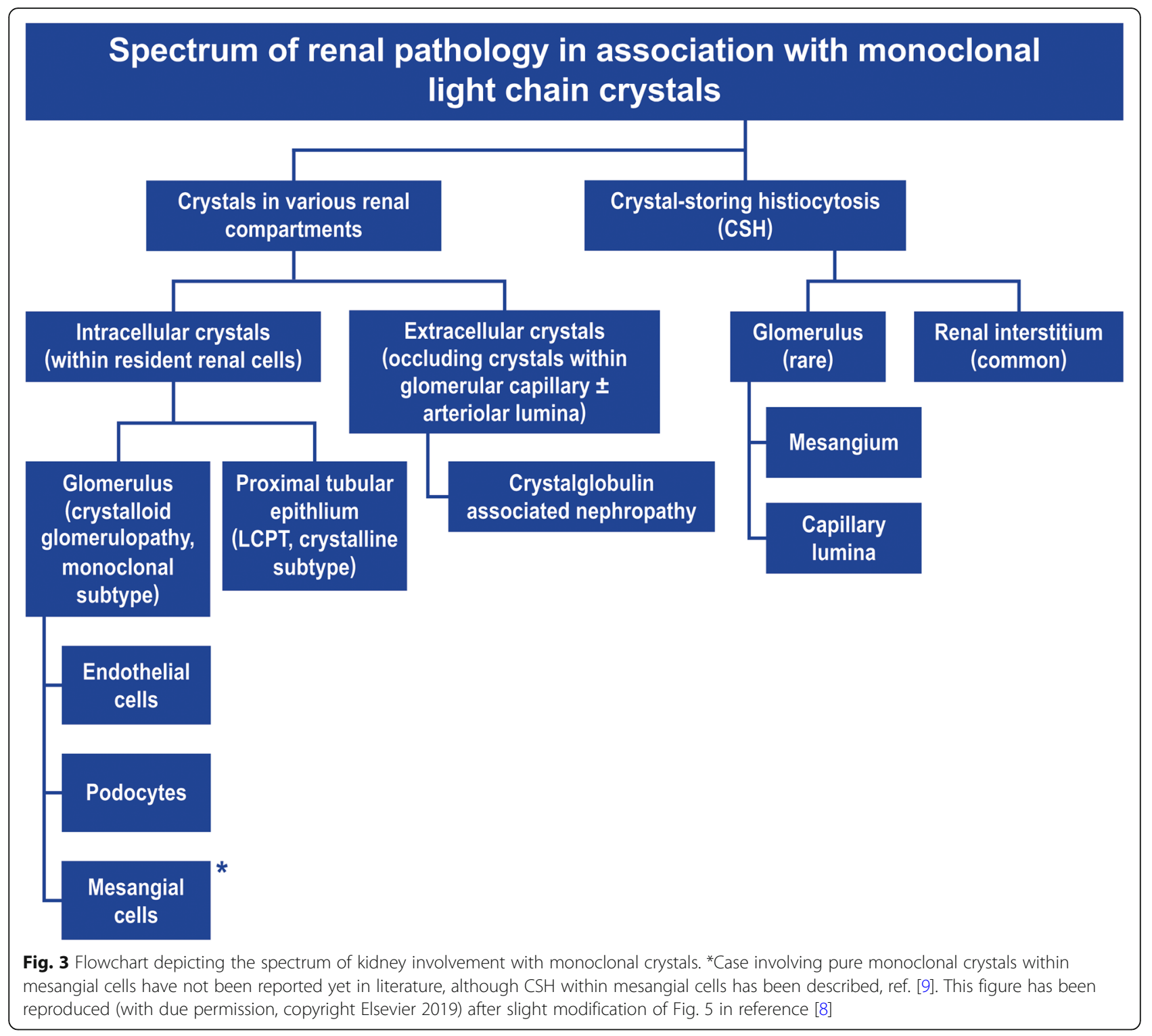

In conclusion, we describe a rare case of CAN in a patient with MBL (CLL subtype) and renal failure and without systemic symptoms, organomegaly, bone pain or lymphadenopathy. Our case highlights the importance of being aware of rare entities like CAN and also stresses the fact that even a small B-cell clone as in MBL should not be ignored [25] as it can sometimes lead to selective kidney dysfunction as MGRS. Our case also shows how IEM can be of immense help in clinching a diagnosis when standard immunofluorescence is equivocal or even falsenegative [20]. Lastly, the case stresses the importance of doing repeat SPEP testing (when initial results are negative) and free light chain assay as a mandatory workup in any patient with suspicion of a monoclonal gammopathy, with the aim of initiating proper treatment and/or follow-up at the earliest [1].

\section{Abbreviations}

CAN: Crystalglobulin-associated nephropathy; MGRS: Monoclonal gammopathy of renal significance; MBL: Monoclonal B-cell lymphocytosis; MM: Multiple myeloma; MGUS: Monoclonal gammopathy of undetermined significance; CLL: Chronic lymphocytic leukemia; IEM: Immunoelectron microscopy

\section{Acknowledgements}

We wish to thank the electron microscopy laboratory of Johns Hopkins University Department of Pathology for the technical processing associated with the immunogold electron microscopy done in this case.

Authors' contributions

RKG (renal pathologist) interpreted the histopathologic, electron microscopic and immunoelectron microscopic data and co-wrote the manuscript with RB (nephrologist) and ABK (internal medicine resident) who looked after the 
patient and were responsible for collecting and analyzing all clinical data. RKG, RB and $A B K$ were assisted in drafting and editing of the manuscript by LJA (senior renal pathologist) and SN (senior nephrologist). LJA also assisted RKG in interpreting the pathologic data. All authors read and approved the final manuscript.

\section{Funding}

No funding was obtained for this study.

Availability of data and materials

All the data supporting our findings is contained within the manuscript

\section{Ethics approval and consent to participate}

Need for approval was waived as it is a retrospective case report; no human participants were used.

\section{Consent for publication}

Written informed consent was obtained from the patient for publication of this case report.

\section{Competing interests}

The authors declare that they have no competing interests.

\section{Author details}

${ }^{1}$ Department of Pathology, SUNY Upstate Medical University, 750 E Adams Street, Syracuse, NY 13210, USA. ²Department of Pathology, Johns Hopkins University School of Medicine, Baltimore, MD, USA. ${ }^{3}$ Department of Medicine, SUNY Upstate Medical University, Syracuse, NY, USA. ${ }^{4}$ Department of Medicine and Nephrology, SUNY Upstate Medical University, Syracuse, NY, USA. ${ }^{5}$ Department of Nephrology, SUNY Upstate Medical University, Syracuse, NY, USA.

Received: 1 January 2020 Accepted: 19 April 2020

Published online: 18 May 2020

\section{References}

1. Gupta V, El Ters M, Kashani K, et al. Crystalglobulin-induced nephropathy. J Am Soc Nephrol. 2015;26:525-9.

2. Leung N, Bridoux F, Batuman V, et al. The evaluation of monoclonal gammopathy of renal: a consensus report of the international kidney and monoclonal Gammopathy research group. Nat Rev Nephrol. 2019;15:45-59.

3. Sethi S, Rajkumar SV, D'Agati VD. The complexity and heterogeneity of monoclonal immunoglobulin-associated renal diseases. J Am Soc Nephrol. 2018:29:1810-23.

4. Stokes MB, Valeri AM, Herlitz L, et al. Light chain proximal tubulopathy: clinical and pathologic characteristics in the modern treatment era. J Am Soc Nephrol. 2016;27:1555-65.

5. Matsuyama N, Joh K, Yamaguchi Y, et al. Crystalline inclusions in the glomerular podocytes in a patient with benign monoclonal gammopathy and focal segmental glomerulosclerosis. Am J Kidney Dis. 1994;23:859-65.

6. Vankalakunti M, Bonu R, Shetty $\mathrm{S}$, et al. Crystalloid glomerulopathy in monoclonal gammopathy of renal significance (MGRS). Clin Kidney J. 2014; 7:296-8.

7. Yu XJ, Zhou XJ, Wang SX, et al. Monoclonal light chain crystalline podocytopathy and tubulopathy associated with monoclonal gammopathy of renal significance: a case report and literature review. BMC Nephrol. 2018; 19:322.

8. Gupta RK, Rosenberg AZ, Bagnasco SM, Arend L. Renal crystal-storing histiocytosis involving glomeruli - a comprehensive clinicopathologic analysis. Ann Diagn Pathol. 2019;43:151403. https://doi.org/10.1016/j. anndiagpath.2019.151403.

9. Sethi S, Cuiffo BP, Pinkus GS, Rennke HG. Crystal-storing histiocytosis involving the kidney in a low-grade B-cell lymphoproliferative disorder. Am J Kidney Dis. 2002;39(1):183-8.

10. Von Bonsdorff B, Groth H, Packalen T. On the presence of a high-molecular crystallizable protein in the blood serum in myeloma (abstract). Folia Haematol. 1938;59:184

11. Leung N, Buadi FK, Song KW, et al. A case of bilateral renal arteria thrombosis associated with cryocrystalglobulinemia. NDT Plus. 2010;3:74-7.

12. Maitre E, Troussard X. Monoclonal BB-cell lymphocytosis. Best Pract Res Clin Haematol. 2019;32(3):229-38.
13. Strati $\mathrm{P}, \mathrm{Nasr} \mathrm{SH}$, Leung $\mathrm{N}$, et al. Renal complications in chronic lymphocytic leukemia and monoclonal B-cell lymphocytosis: the Mayo Clinic experience. Haematologica. 2015;100(9):1180-8.

14. Poitou-VerkinderAL FA, Drieux F, et al. The spectrum of kidney pathology in B-cell chronic lymphocytic leukemia/small lymphocytic lymphoma: a 25year multicenter experience. PLoS One. 2015;10(3):e0119156.

15. Li S-J, Chen H-P, Chen Y-H, et al. Renal involvement in non-Hodgkin lymphoma: proven by renal biopsy. PLoS One. 2014;9(4):e95190.

16. D'Costa MR, Dalvin LA, Manohar S, et al. Crystalglobulin-induced nephropathy and keratopathy. Kidney Med. 2019;1:71-4.

17. Ravindran A, Go RS, Fervenza FC. Thrombotic microangiopathy associated with monoclonal gammopathy. Kidney Int. 2017;91:691-8.

18. Nasr SH, Fidler ME, Said SM. Paraffin immunofluorescence: a valuable ancillary technique in renal pathology. Kidney Int Rep. 2018;3:1260-6.

19. Gu X, Barrios R, Cartwright J, et al. Light chain crystal deposition as a manifestation of plasma cell dyscrasias: the role of immunoelectron microscopy. Hum Pathol. 2003;34:270-7.

20. Herrera GA, Turbat-Herrera EA. Ultrastructural immunolabeling in the diagnosis of monoclonal light-and-heavy-chain-related renal diseases. Ultrastruct Pathol. 2010:34:161-73.

21. Lobo VA, Subramaniam K, Bidaye MA, Deshpande S. Type I Cryoglobulinemic nephritis in a patient of monoclonal Gammopathy of renal significance. Indian J Nephrol. 2018;28:65-8.

22. Khalighi MA, Al-Rabadi L, Chalasani M, et al. Staphylococcal infection-related glomerulonephritis with cryoglobulinemic features. Kidney Int Rep. 2018;3: 1128-34.

23. Hashimoto R, Toda T, Tsutsumi H, et al. Abnormal N-glycosylation of the immunoglobulin $\mathrm{G}$ kappa chain in a multiple myeloma patient with crystalglobulinemia. Int J Hematol. 2007;85:203-6.

24. Aucouturier $P$, Bauwens $M$, Khamlichi $A A$, et al. Monoclonal lg $L$ chain and $L$ chain $V$ domain fragment crystallization in myeloma-associated Fanconi's syndrome. J Immunol. 1993;150:3561-8.

25. Merlini G, Stone MJ. Dangerous small B-cell clones. Blood. 2006;108:2520-30.

\section{Publisher's Note}

Springer Nature remains neutral with regard to jurisdictional claims in published maps and institutional affiliations.
Ready to submit your research? Choose BMC and benefit from:

- fast, convenient online submission

- thorough peer review by experienced researchers in your field

- rapid publication on acceptance

- support for research data, including large and complex data types

- gold Open Access which fosters wider collaboration and increased citations

- maximum visibility for your research: over $100 \mathrm{M}$ website views per year

At BMC, research is always in progress.

Learn more biomedcentral.com/submissions 